\title{
VIEWPOINT
}

\section{The irritable bowel syndrome}

\author{
N.B. HERSHFIELD, MD, FRCPC, FACP
}

$\mathrm{T}$ HE IRRITABLE BOWEL SYNDROME IS THE MOST COMMON diagnosis in gastroenterology practice (1). Most gastroenterologists feel that this syndrome is the most difficult to treat $(2,3)$. This article will attempt to review the clinical features and the known physiologic and psychologic abnormalities and treatment for this condition.

There is no acceptable definition of the irritable bowel syndrome, but it can be defined as a constellation of gastrointestinal disorders that have no organic basis, that is, no bacteriologic, pathologic or biochemical changes. Historically it was probably alluded to by Osler in his Principles and Practice of Medicine in 1892 (4).

It is extremely common and is stated to be responsible for anywhere from 40 to $70 \%$ of a gastroenterology practice (5). In addition, both Drossman and Thompson $(6,7)$ pointed out that there was a large proportion of the normal population that had similar symptoms who did not consult their physicians.

The clinical presentation of the irritable bowel syndrome is quite variable. The sine qua non of the syndrome is altered bowel function and abdominal pain in association with loose stools and/or constipation. Numerous other symptoms can be present including bloating, gas, dyspepsia, mucus in the stool, straining, fecal incontinence and urgency (8-10).

In general, the signs are minimal and an extensive search for organic causes may be carried out. Recently it has been suggested by Manning and Thompson (10) that a positive diagnosis should be made and that investigation be kept to a minimum. These investigations should include history, physical examination, sigmoidoscopy, complete blood count, per-

Clinical Professor, Department of Medicine, University of Calgary, 711 South Tower, 3031 Hospital Drive NW. Calgary, Alberta T2N 2T9 haps barium contrast enemas, $x$-rays, stools for ova and parasites and occult blood and possibly a test for lactase deficiency.

This approach has been investigated by Kruis (11), who found that after a two year follow-up of patients who had minimal investigation, he was able to confidently make the diagnosis of the irritable bowel syndrome, and no further investigation was necessary. In the long term follow-up of these patients it was demonstrated that irritable bowel syndrome was a 'safe diagnosis' and that few if any other organic disorders were missed $(12,13)$.

\section{PATHOPHYSIOLOGY}

An extensive body of research exists trying to categorize the pathophysiology of the irritable bowel syndrome. There is no doubt that a bowel motility disorder is at work, but the precise etiology is not known. In these patients the gut appears to overact to just about every stimulus (14). Patients have exaggerated motor responses to cholecystokinin which is released on eating $(15,16)$. Because of this, patients report more discomfort than normal when subjected to stimuli of various natural or experimentally induced methods (16).

These studies have led to questions about the irritable bowel patient, whether or not they have some differences in their pain thresholds or tolerance, and recently Cook and his co-workers (17) showed that patients actually have higher pain thresholds than healthy controls. Therefore, their pain is similar to that of patients who have so-called organic disease, but the question as to why they report symptoms more often is as yet unanswered.

Myoelectrical abnormalities apparently do exist in the irritable bowel syndrome with some investigators reporting a greater percentage of 3 cycle per minute slow wave activity in the 
colon. This apparently predisposes these patients to have abnormal motor responses $(18,19)$. Other workers, however, have not been able to reproduce these results $(20,21)$.

Still other workers have suggested that the abnormal motor responses in the irritable bowel can be generalized to the entire gastrointestinal tract and the suggestion has therefore been made that the entire gut is irritable in these particular individuals (22).

One of the hallmark symptoms of the irritable bowel syndrome, gaseousness, has been shown by Lasser and his coworkers (23), not to be associated with any increase in the volume or the type of gas, but that the abnormality is due to abnormal contraction of the small intestine. Comare and colleagues (24) demonstrated also that the small bowel was involved in the syndrome.

In summary, there are many motor disturbances described in the irritable gut syndrome. Standardization of the techniques is obviously needed, plus further information that can be ascer tained only when the methods of investigating intestinal motility are universal.

Aside from the above hypothesis, another suggestion has been made by Jones (25) that food intolerance is the inciting factor in the irritable bowel. Up to this point, however, no corroborative evidence is available.

It is obvious that there is no single abnormality in the irritable bowel syndrome. Despite extensive investigation, it is unlikely that one specific abnormality will be uncovered. It is certainly possible that all of the factors; abnormal motility, food intolerance and abnormal myoelectrical activity, may all be implicated either singly or in conjunction with each other.

\section{PSYCHOSOCIAL FACTORS}

Numerous authors have demonstrated a relationship between the irritable bowel syndrome and behaviour or psychosocial factors. Almey, in 1951, summarized his extensive investigations into the studies of stress and the gut (26). He and his collaborators demonstrated changes in pressure in the rectosigmoid area and also in the vascularity of the gut in response to various inciting factors. He found that changes in those parameters correlated with specific emotions. As an example, when the patients were hostile, sigmoid pressure increased; yet when the patients were sad, the pressure decreased. He proposed that these patients were neurotic and psychologically ill.

Mendelloff and his co-workers (27) demonstrated that patients who were hospitalized with the irritable bowel syndrome were more able to relate highly significant stressful events prior to their admission than those patients with ulcerative colitis and healthy controls.

In their classic study, Chaudhaury and Truelove (28) also showed that antecedent stress was far more common in patients with irritable bowel syndrome than in a control group of patients. Early life experiences have been shown to be far more common in patients with the syndrome than their healthy cohorts $(27,28)$.

In other respects, irritable bowel sufferers apparently are different from the control population in that they have been shown to have a specifically higher index of disruption of their daily living (29). They report more minor illnesses and multiple symptomatology than a control group consisting of patients with peptic ulcer disease. They also tend to seek health care for minor illnesses, far beyond the control population $(28,30)$. It has been suggested that if this illness behaviour has been reinforced during the early years, this may lead to a 'conditioned bowel response' to stressful events later in life (31).

Because such a high prevalence of psychiatric diagnoses and behaviour has been found, a theory has been proposed, that the irritable bowel syndrome is actually a psychiatric disorder (32). As Osler stated in his original article in Principles and Practice of Medicine, modern investigation has shown that these patients are more psychoneurotic than normal (33-37). These diagnoses include depression, hysteria and anxiety, and are not appreciated by the consulting physician, whether a general practitioner or a specialist.

Despite the great limitations of these kinds of studies, and the fact that many patients with the irritable bowel syndrome are not psychologically abnormal, it should be understood that the possibility of a psychiatric disturbance in these patients should be considered; especially on the initial encounter and particularly when discussing therapy.

Drossman (29) has studied this extensively to see if he could further delineate patients who see physicians with symptoms not related to the irritable bowel syndrome. He found that these patients were different from 'nonpatients' and normal subjects in a psychosocial fashion and that the nonpatients were not psychosocially different from normal subjects. Minnesota Multiphasic Personality Inventory (MMPI) scores, however, in patients with the irritable bowel syndrome were significantly higher.

This study would imply that those patients who seek medical care and therapy should be evaluated carefully by physicians in order to treat them most efficiently, as the problem seems to be multifactorial.

\section{TREATMENT}

In regard to treatment of this enigmatic condition, there are as many treatments as there are symptoms. Probably the most important feature is the establishment of a careful treatment regimen, and most importantly a carefully thought out therapeutic relationship. Many authors, expert in the therapy of this condition, stress the latter dictum. Psychologic and medical treatment must be dovetailed by the physician and specialized to the requirements of the individual patient. Since therapy is that of a long term relationship, this has to be understood almost at the beginning of treatment.

It is important to understand that these patients are ex. tremely high placebo responders, anywhere from $35 \%$ to $75 \%$ (38). This makes evaluation of trials of the various kinds of treatment extremely difficult. It is for this reason that long term treatment with drugs is frequently doomed to failure. Perhaps nonpharmaceutical therapy of the condition, which has been suggested recently, may be the best strategy for successful management. 
Dietary modification has been suggested, especially increasing fibre in the diet. Numerous studies on the management of the irritable bowel syndrome with bran have been carried out and it has been shown that it is effective for those patients that are primarily constipated (39) and possibly in those patients who have abdominal pain. It is important to note, however, that in many double blind studies bran and/or fibre is not effective in the overall management of the irritable bowel syndrome (41). The best thing one can say about fibre is that it is safe and has minimal side effects! Jones and others (25) suggests elimination diets as a treatment of this condition, but corroboration of this mode of therapy is lacking.

There are numerous medications used in the treatment of the irritable bowel syndrome, but they are extremely difficult to evaluate because of the high placebo response noted in these patients (42). These drugs have a very high incidence of side effects and, for example, are particularly devastating in elderly males in whom prostatism is so common. Since a definite relationship between the motor abnormality of the gut and symptoms has not been established, their use should be tempered with caution. Recently, peppermint oil has been suggested as a therapy for this condition (42); it appears to help those with pain or constipation. Peppermint oil has very few side effects and may well be valuable, although its effect may be placebo related (38).

Antidepressants have been used, especially in those patients that have signs of depression (37). The benefits that are reported of these drugs may well be due to very careful patient selection (44), and it is certainly possible that their effect is mainly due to their anticholinergic properties. In two studies that appear to show a value for these antidepressants, no control groups were used, therefore, interpretation is impossible $(45,46)$.

The treatment of the irritable bowel syndrome with other medications, including anxiolytics and loperamide, are limited by the small groups of patients used, and careful patient selection. Obviously in those patients who have diarrhea predominance, antidiarrheal agents may be valuable; and anxiolytics are valuable for the emotional symptoms of some of these patients $(35,37)$.

Aside from pharmacological therapy, recent work has suggested that psychological and behavioural treatment is valuable in treating the condition. Svedlund (35) reported good results with insight and cognitive psychotherapy against rout-

\section{REFERENCES}

1. Mitchell CM, Drossman DA. Survey of the AGA membership relating to patients with functional GI disorders.

Gastroenterology 1987:92:1282-4.

2. Thompson WG. The irritable bowel. Gut 1984;25:305-20.

3. Kirsner JB. The irritable bowel syndrome. Arch Intern Med 1981; 141:635-9.

4. Drossman DA. The physician and the patient. Revue of the psychosocial GI literature with an integrated approach to the patient. In: Sleisinger MH, Fordtran JF, eds. Gastrointestinal Disease: Pathophysiology, Diagnosis and Management, 3rd edn. Philadelphia: WB Saunders \& Co, 1983:3-20.

5. Fielding JF. The year of in outpatients with the irritable bowel ine medical treatment in a controlled trial. There was significant improvement in all symptoms in patients receiving psychologic therapy. At the end of one year, patients treated with nonpharmacological means were far better than the medically treated group, who either remained the same or deteriorated.

Another study of hypnosis in the treatment of the irritable bowel syndrome also showed improvement in all symptoms in a small group of patients (47).

Various other types of behavioural therapy, including various relaxation techniques, transcendental meditation and biofeedback, have been cited, but there have been few adequate studies $(48,49)$. Undoubtedly, other forms of alternative medicine' therapy will surface as time goes on.

As with all multifactorial illnesses (of which the irritable bowel syndrome must surely be a classic), from time to time 'new diseases' are uncovered that have been previously labelled the irritable bowel syndrome. Specifically in the socalled diarrhea predominant irritable bowel syndrome, at least a few conditions should be considered before diagnosing the patient. These include sorbitol-induced diarrhea (50), lactase deficiency (51), collagenous colitis (52) (a conditon in which the bowel looks perfectly normal - both at $\mathrm{x}$-ray and endoscopy, and for which a biopsy is required), and idiopathic bile salt or bile acid diarrhea (52).

There is no general agreement on whether or not abdominal pain of uncertain origin without bowel habit change should be included in the irritable bowel syndrome. My own bias is not to do so, but opinions vary widely (53).

In summary, the irritable bowel syndrome is a ubiquitous disorder which has generated a considerable amount of investigation over the past two decades. As yet there is no agreement as to the etiology of the condition and indeed, no specific reproducible motor abnormality of the gut has been elucidated. The treatment is uncertain except to say that support psychotherapy and occasionally anticholinergic medications appear to be beneficial. There is no agreement as to whether these patients suffer from psychological problems, and yet most physicians would agree that the problem is of that nature.

Although the condition is nonfatal, it leads to a great deal of discomfort and frequently extensive, dangerous and useless investigations and therapy in a vain attempt to try to control the problem. Quite obviously further investigation is required, but it is my opinion that we are not much further in the understanding of the condition than Osler was in 1892.

syndrome. Ir J Med Sci 1977; 146:162-6.

6. Drossman DA, Sandler RS, McKee DC, Lovitz AJ. Bowel patterns among subjects not seeking health care: Use of a questionnaire to identify a population with bowel dysfunction. Gastroenterology 1982;83:529-34.

7. Thompson WG, Heaton KW. Bowel disorders in apparently healthy people. Gastroenterology 1980;79:283-8.

8. Thompson WG. Irritable bowel syndrome, Can Med Assoc J 1986; 134:111-3.

9. Drossman DA, Howell DW, Sessions JT. The irritable bowel syndrome. Gastroenterology 1977;73:811-22.

10. Manning AP, Thompson WG, Heaton KW, Morris AF. Toward a positive diagnosis of the irritable bowel. Br Med J 1978:2:653-4. 
11. Kruis W, Thieme $\mathrm{CH}$, Weinzierlm, et al. A diagnostic score for the irritable bowel syndrome: Its value in exclusion of organic disease. Gastroenterology 1984;87:1-7.

12. Whorwell PJ, McCallum M, Cread FH, Roberts CT. Noncolonic features of the irritable bowel syndrome. Gut 1986;27:37-40.

13. Svendsen JH, Mond LK, Anderson JR. Irritable bowel syndrome - prognosis and diagnostic safety. A five-year follow-up study. Scand J Gastroenterol 1985;20:415-8.

14. Whitehead WE. The irritable bowel syndrome: Physiological and psychological mechanisms. In: Whitehead WE, Schuster MM, eds. Gastrointestinal Disorders. Behavioural and Physiologic Basis for Treatment. New York: Academic Press, 1985:170-209

15. Harvey RF, Read AE. Effect of cholecystokinin on colonic motility and symptoms in patients with the irritable bowel syndrome. Lancet 1973;i:1-6.

16. Whitehead WE, Engel BT, Schuster MM. Irritable bowel syndrome. Physiological and psychological differences between diarrhea predominant and constipation predominant patients. Dig Dis Sci 1980;26:404-13.

17. Cook IJ, van Eeden A, Collins SM. Patients with irritable bowel syndrome have greater pain tolerance than normal subjects. Gastroenterology 1987;93:727-9.

18. Snape WJ Jr, Carlson GM. Matarazzo SA, Cohen S. Evidence that abnormal myoelectrical activity produces colonic motor dysfunction in the irritable bowel syndrome. Gastroenterology 1977;72:383-7.

19. Taylor I, Darby C, Hammond P, Basu P. Is there a myoelectrical abnormality in the irritable colon syndrome? Gut 1978;19:391-5.

20. Latimer PR, Sarna S, Campbell D, et al. Colonic motor and myoelectrical activity: A comparative study of normal subjects, psychoneurotic patients, and patients with the irritable bowel syndrome. Gastroenterology 1981;80:893-901.

21. Welgan P, Meshkinpour H, Hoehler F. The effects of stress on colon mptor and electrical activity in the irritable bowel syndrome. Psychosom Med 1985;47:139-49.

22. Richter JE, Obrecht WF, Bradley LA, Young LD, Anderson KO Psychological comparison of patients with nutcracker esophagus in the irritable bowel syndrome. Dig Dis Sci 1986;31:131-8.

23. Lasser RB, Bond JH, Leavitt MD. The role of intestinal gas in functional midabdominal pain. N Engl J Med 1975;293:524-6.

24. Kumar D, Wingate DL. The irritable bowel syndrome, a paroxysmal motor disorder. Lancet 1985;ii:973-7.

25. Jones AV, McLaughan P. Shorthouse M, Workman E. Food intolerance: A major factor in the pathogenesis of irritable bowel syndrome. Lancet 1982; ii: 1115-7.

26. Almy TP. Experimental studies on the irritable colon. Am J Med 1951;9:60-67.

27. Lowman BC, Drossman DA, Cramer EM, McKee DC. Recollection of childhood events in adults with irritable bowel syndrome. J Clin Gastroenterol 1987;9:324-30.

28. Hislop IG. Childhood deprivation. An antecedent of the irritable bowel syndrome. Med J Aust 1979;1:372-4

29. Drossman DA, McKee DC, Sandler RS, et al. Psychosocial factors in the irritable bowel syndrome: A multivariate study of patients and nonpatients with IBS. Gastroenterology 1987:92:1374.

30. Whitehead WE, Winget C. Fedoravicius AS, Wooley S, Blackwell B. Learned illness behaviour in patients with irritable bowel syndrome and peptic ulcer. Dig Dis Sci 1982;27:202-8.

31. Latimer PR. Irritable bowel syndrome, a behavioural model. Behav Res Ther 1981; 19:475-83.

32. Young S], Alpers DA, Norland CC, Woodruff RA. Psychiatric illness in the irritable bowel syndrome. Practical implications for the primary physician. Gastroenterology 1976;70:162-6.

33. Palmer RL, Krist AH, Sonehill E, Waller WL, Misiewicz JJ. Psychological characteristics of patients with the irritable bowel syndrome. Postgrad Med J 1974:50:416-9.

34. Mendeloff AI, Monk M, Siegel CI, Lilienfeld A. Illness experience and life stresses in patients with irritable colon and ulcerative colitis. An epidemiologic study of ulcerative colitis and regional enteritis in Baltimore in 1960-1964. N Engl J Med $1970 ; 282: 14-7$

35. Svedlund J. Sjodin I, Ottoson, et al. Controlled study of psychotherapy in the irritable bowel syndrome. Lancet 1983;ii:589-91.

36. Lancaster Smith MU, Prout BJ, et al. Influence of drug treatment on the irritable bowel syndrome and its interaction with psychoneurotic morbidity. Acta Psychiatr Scand $1982 ; 66: 33-41$

37. Greenbaum DS. Preliminary report on antidepressant treatment of the irritable bowel syndrome. Comments on comparison to anxiolytic therapy. Psychopharmacol Bull 1984:20:622-8.

38. Longstref GF, Fox DD, Youkeles L, Forsythe AB, Wolochow DA. Psyllium therapy in the irritable bowel syndrome. A double-blind trial. Ann Intern Med 1981:95:53-6.

39. Cann PA, Read NW, Holdworth CD. What is the benefit of coarse wheat bran in cases with irritable bowel syndrome? Gut 1984;25:168-73.

40. Heaton KW. The role of dietary fibre in the irritable bowel syndrome. In: Read NW, ed. The Irritable Bowel Syndrome. New York: Grune and Stratton, 1985.

41. Heaton KW. In: Read NW, ed. The Irritable Bowel Syndrome. New York: Grune and Stratton, 1985;203-29

42. lvey KJ. Are anticholinergics of use in the irritable bowel syndrome? Gastroenterology 1975;68:1300-7.

43. Rees DW, Evans BK, Rhodes J. Treating irritable bowel with peppermint oil. Br Med J 1979;2:835-6.

44. Myran J, Groth H, Larssen SE, Larsen S. The effect of trimipramine in patients with the irritable bowel syndrome. A double-blind study. Scand J Gastroenterol 1982;17:871-5.

45. Steinhart MJ, Wong PY, Zarr ML. Therapeutic usefulness of amitriptyline in the spastic colon syndrome. Int J Psych Med 1981;11:45-57.

46. Cann PA. Read NW. Holdsworth CD, Barends D. Low dose of loperamide in placebo in management of irritable bowel syndrome. Dig Dis Sci 1984:29:239-47.

47. Whorwhal PJ, Prior A, Faragher EB Controlled trial of hypnotherapy in the treatment of the severe refractory irritable bowel syndrome. Lancet 1984; ii: 1232-3.

48. Whitehead WE. Psychotherapy and biofeedback in the treatment of the irritable bowel syndrome. In: Read NW, ed. Irritable Bowel Syndrome. London: Grune and Stratton, 1985:245-56

49. Smart HL, Mayberry JF, Atkinson M. Alternative medicine consultations and remedies in patients with the irritable bowel syndrome. Gut 1986;27:826-8.

50. Hymans JS. Sorbitol intolerance. An unappreciated cause of functional gastrointestinal complaints. Gastroenterology 1983;84:30-4.

51. Newcomber AD, McGill DB. Irritable bowel syndrome. Role of lactase deficiency. Mayo Clinic Proc 1983;58:339-42.

52. Thyasen EH, Pederson L. Idiopathic bile acid catharsis. Gut 1976:17:1965-8.

54. Thompson WG. Irritable bowel syndrome. In: Read NW, ed. Irritable Bowel Syndrome. London: Grune and Stratton, 1985:3-16. 


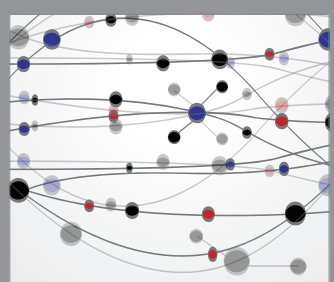

The Scientific World Journal
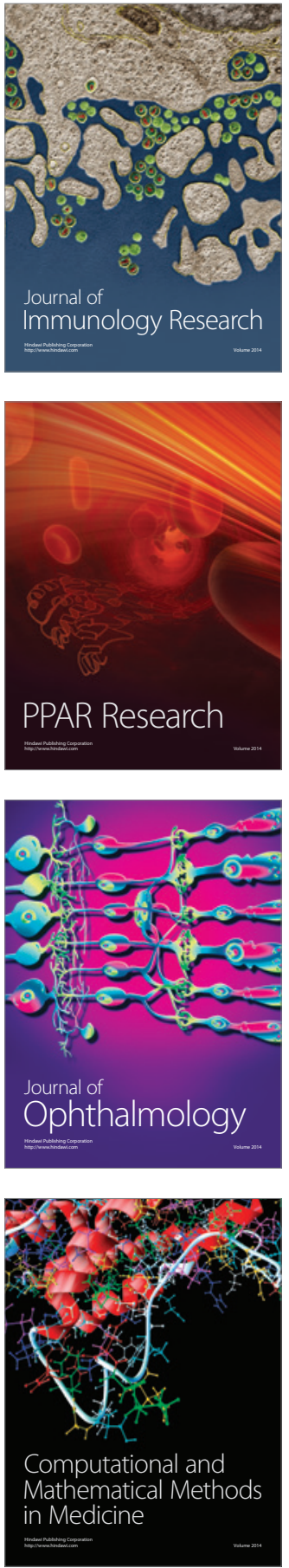

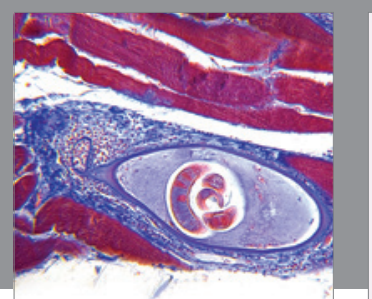

Gastroenterology Research and Practice

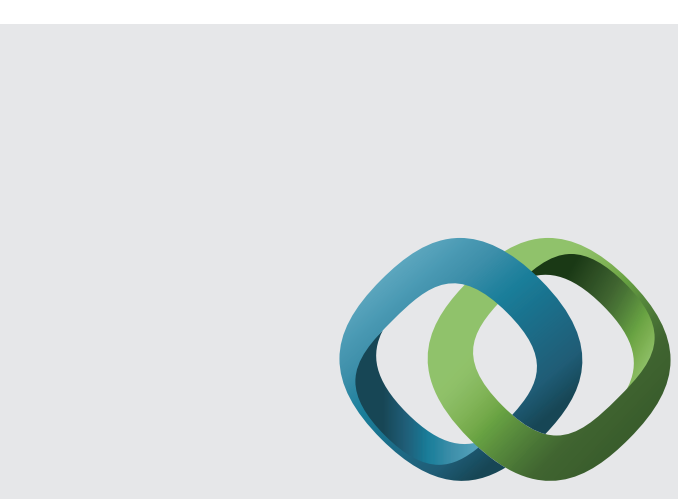

\section{Hindawi}

Submit your manuscripts at

http://www.hindawi.com
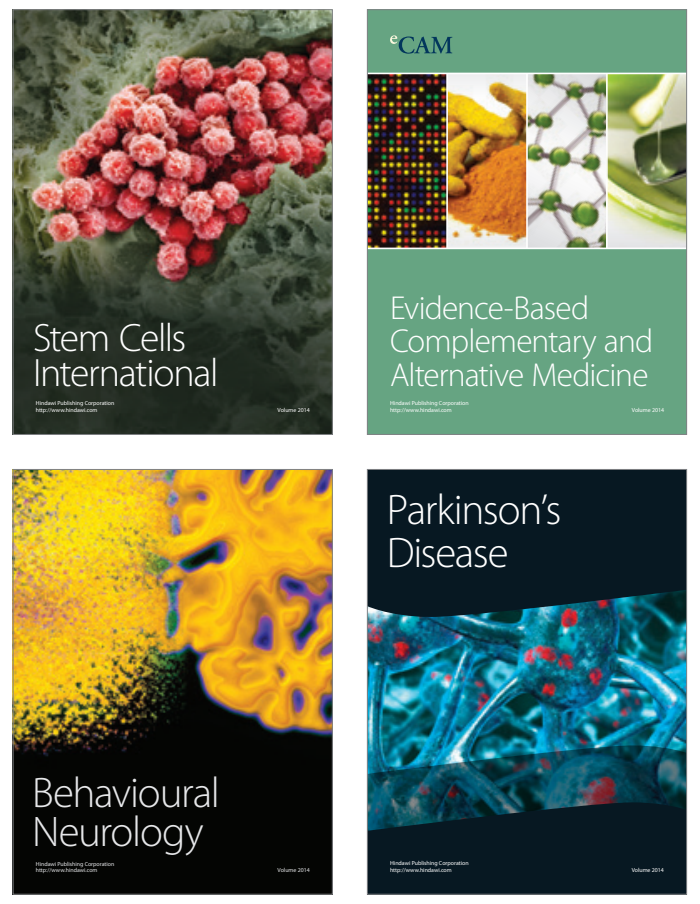
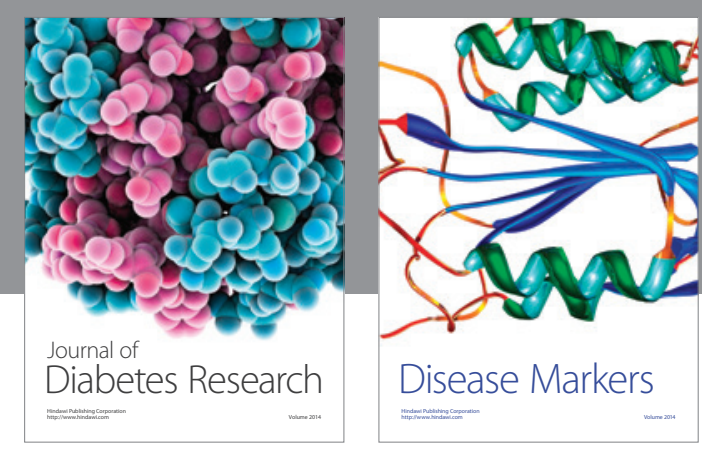

Disease Markers
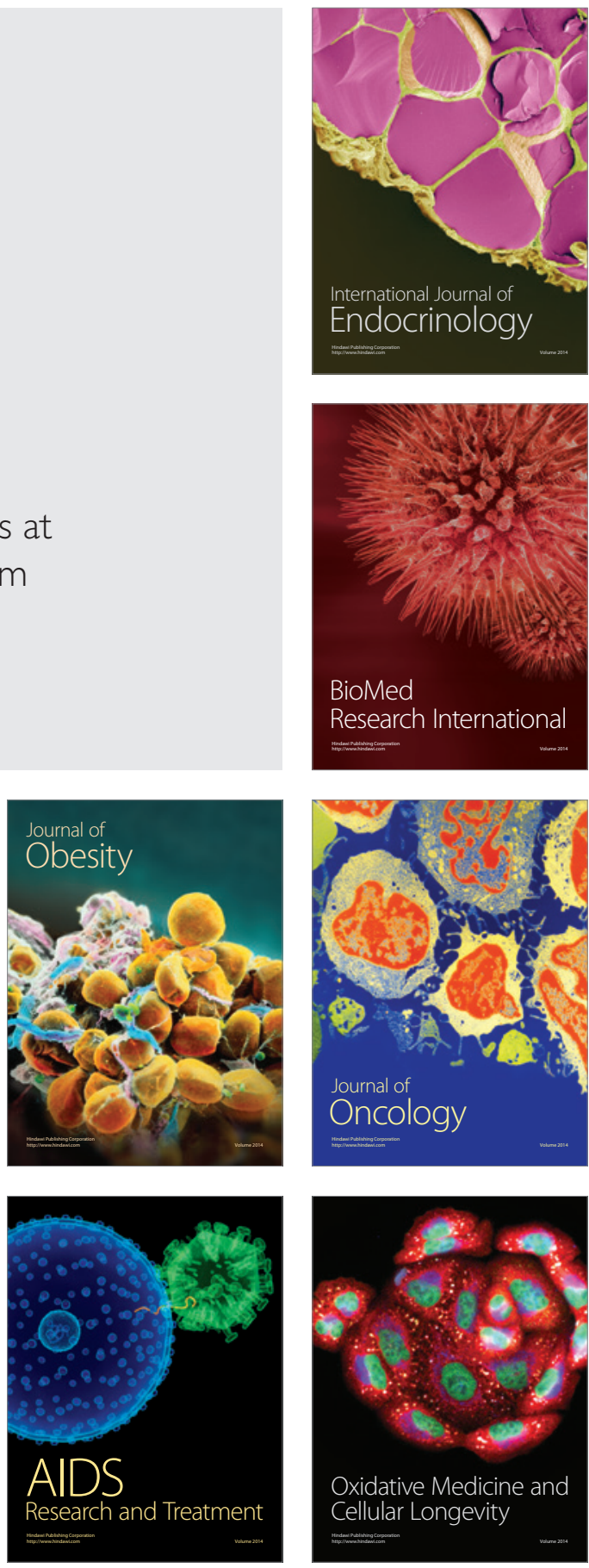